Adıyaman Üniversitesi Sağlık Bilimleri Dergisi, 2020;6(3):401-405

doi:10.30569.adiyamansaglik.742915

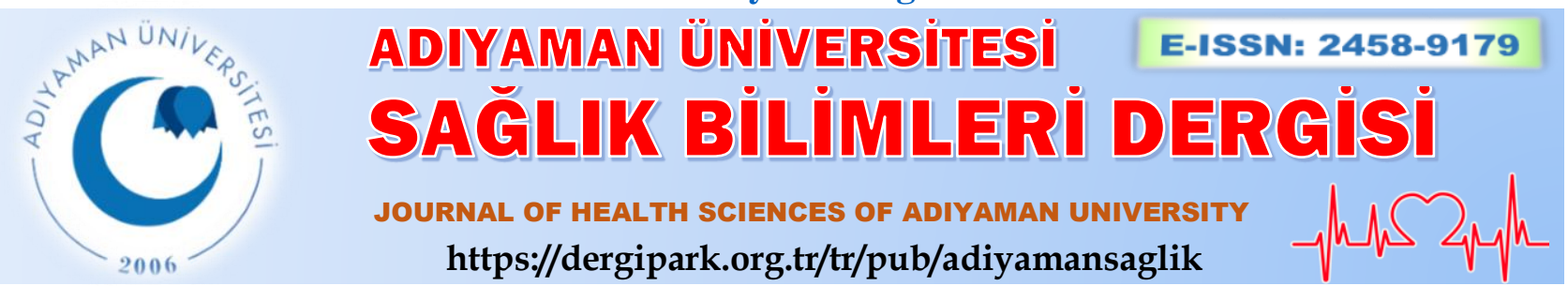

Olgu Sunumu/Case Report

\title{
Paratubal dev seröz kistadenom: olgu sunumu
}

\section{Paratubal giant serous cystadenoma: case report}

\author{
Mehmet BÜLBÜL ${ }^{1 @(D)}$, Necla KAYA ${ }^{1(\mathrm{C})}$ \\ ${ }^{1}$ Adıyaman Üniversitesi, Tıp Fakültesi, Kadın Hastalıkları ve Doğum Anabilim Dalı, 02040, Adıyaman-Türkiye
}

Atıf gösterme/Cite this article as: Bülbül M, Kaya N. Paratubal dev seröz kistadenom: olgu sunumu. $A D Y \ddot{U}$ Sağllk Bilimleri Derg. 2020;6(3):401-405. doi:10.30569.adiyamansaglik.742915

\section{$\ddot{O} \mathbf{z}$}

Çoğunlukla asemptomatik embriyolojik kalıntı olarak karşımıza çıkan paratubal kistler genellikle üreme çağında tanı alırlar. Genellikle küçük boyutlarda olan bu kistler insidental olarak saptanırlar. Çok nadiren komplike olarak cerrahi gerektirebilir. Bu makalede kliniğimizde tedavi ettiğimiz 17 yaşında $30 \times 25 \times 10 \mathrm{~cm}$ boyutlarındaki pelvik kitle tanılı vakayı sunmayı amaçladik. Laparatomi ile kist eksizyonu uygulanan hastadan $5 \mathrm{~kg}$ ağırlıkta paratubal kist çıkarıldı. Histopatolojik değerlendirmede paratubal seröz kistadenom tanısı konulan hasta şifa ile taburcu edildi. Sonuç olarak nadirde olsa çok büyük boyutlarda basit görünümlü kistik pelvik kitlelerde paratubal seröz kistadenom tanısı akılda tutulmalıdır.

Anahtar Kelimeler: Paratubal Kist; Pelvik Kitle; Seröz Kistadenom;

\begin{abstract}
Paratubal cysts, which mostly appear as asymptomatic embryological residues, are generally diagnosed in reproductive age. These cysts, which are generally small in size, are detected incidentally. They are rarely complicated and may require surgery. In this article, we presented a 17 -year old $30 \times 25 \times 10 \mathrm{~cm}$ pelvic mass diagnosed case that we treated in our clinic. A $5 \mathrm{~kg}$ paratubal cyst was removed from the patient who underwent cyst excision with laparotomy. The patient was diagnosed with paratubal serous cystadenoma in histopathological evaluation. The patient was discharged with healing. In conclusion, the diagnosis of paratubal serous cystadenoma should be kept in mind in very large sizes of simple-looking cystic pelvic masses.
\end{abstract}

Keywords: Paratubal Cyst; Pelvic Mass; Serous Cystadenoma.

Yazışma Adresi/Address for Correspondence: Mehmet BÜLBÜL, Adıyaman Üniversitesi, Tıp Fakültesi, Kadın Hastalıkları ve Doğum Anabilim Dalı, 02040, Adıyaman-Türkiye, E-mail: mehmetbulbulmd@gmail.com

Geliș Tarihi/Received:26.05.2020Ｋabul Tarihi/Accepted:11.08.2020

Yayım Tarihi/Published online:03.12.2020

Bu eser, Creative Commons Atıf-GayriTicari 4.0 Uluslararası Lisansı ile lisanslanmıștır. Telif Hakkı @ 2020 Adıyaman Üniversitesi Rektörlüğü

Bu makale araştırma ve yayın etiğine uygun hazırlanmıştır. 


\section{Giriş}

Paramezonefrik, mezonefrik kalıntılardan kaynaklanan paratubal kistler broad ligament içine büyüyen overden bağımsız lezyonlardır. Tüm yaş gruplarında görülse de üreme çağındaki kadınlarda daha sık izlenmektedir. Çoğunlukla asemtomatik olarak rutin muayene sirasinda insidental olarak saptansa da nadiren büyük boyutlara ulaşarak semptomatik olabilirler. ${ }^{1,2}$ Diğer pelvik kitlelerle ayırıcı tanısı zor olduğu için klinik değerlendirme önemlidir. Tedavide kist eksizyonu genellikle yeterlidir. ${ }^{3} \mathrm{Biz}$ de bu yazıda 17 yaşında bir kadında 5 kg ağırlığa ulaşan seröz paratubal kist vakasını sunduk.

\section{Olgu Sunumu}

Helsinki deklarasyonuna uyularak bu olgu sunumu için hastanın yazılı onamı alındı. On yedi yaşında, bekâr kadın hastanın 4 ay öncesine kadar şikâyeti yoktu. Karnında hızla büyüyen kitle ve sağ kasık ağrısı şikayetleri ile polikliniğimize başvuran hastanın abdominal ultrason muayenesinde tüm karn dolduran douglastan ksifoide kadar uzanan anekoik kist izlendi (Şekil 1). Tümör belirteçlerinden CA125: 34,7 u/ml, CA15-3: $10,4 \mathrm{u} / \mathrm{ml}$ saptand1. Manyetik Rezonans Görüntüleme (MRG) incelemesinde; Sağ adneksiyal lojdan köken alıp pelvisi dolduran ve abdominal bölgeye doğru uzanım gösteren yaklaşık 12x11x24 cm boyutta, sınırları kesite tamamen girmeyen kistik lezyon saptand1 (Şekil 2).

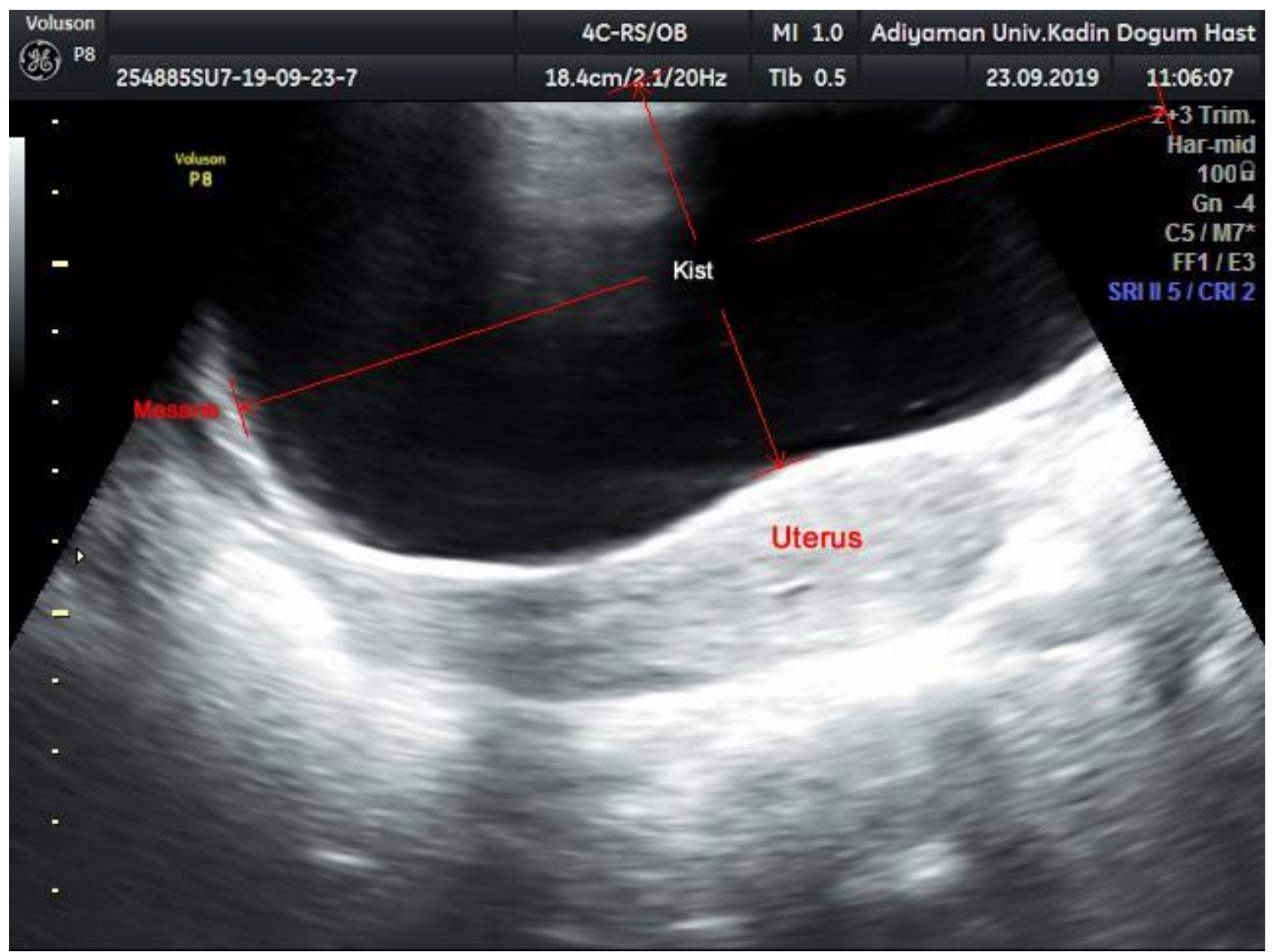

Şekil 1. Pelvik kistik kitlenin ultrasonografik görünümü. Uterus, mesane ve kistin komşulukları görünmektedir.

Preoperatif hazırlık sonrası orta hat insizyon ile batına girildi. Batın içini tamamen dolduran diafragma altına kadar uzanan overden bağımsız, retroperitoneal alana uzanan yaklaşı $35 \times 25 \times 10 \mathrm{~cm}$ ölçülerinde seröz kistik kitle izlendi (Şekil 3).
Kist yüzeyi düzgün, transparan görünümde ve üzerinde uzanan tuba uterina yaklaşı $20 \mathrm{~cm}$ boyunda idi. Ayrica explorasyonda uterus, sol fallop tüp ve over normal görünümdeydi. Kist eksizyonu yapılarak frozen incelemeye gönderildi. Beş kilogramlık kistin frozen 
sonucu seröz kistadenom gelmesi üzerine ikinci günde komplikasyonsuz taburcu edildi. ameliyata son verildi. Hasta ameliyat sonrası

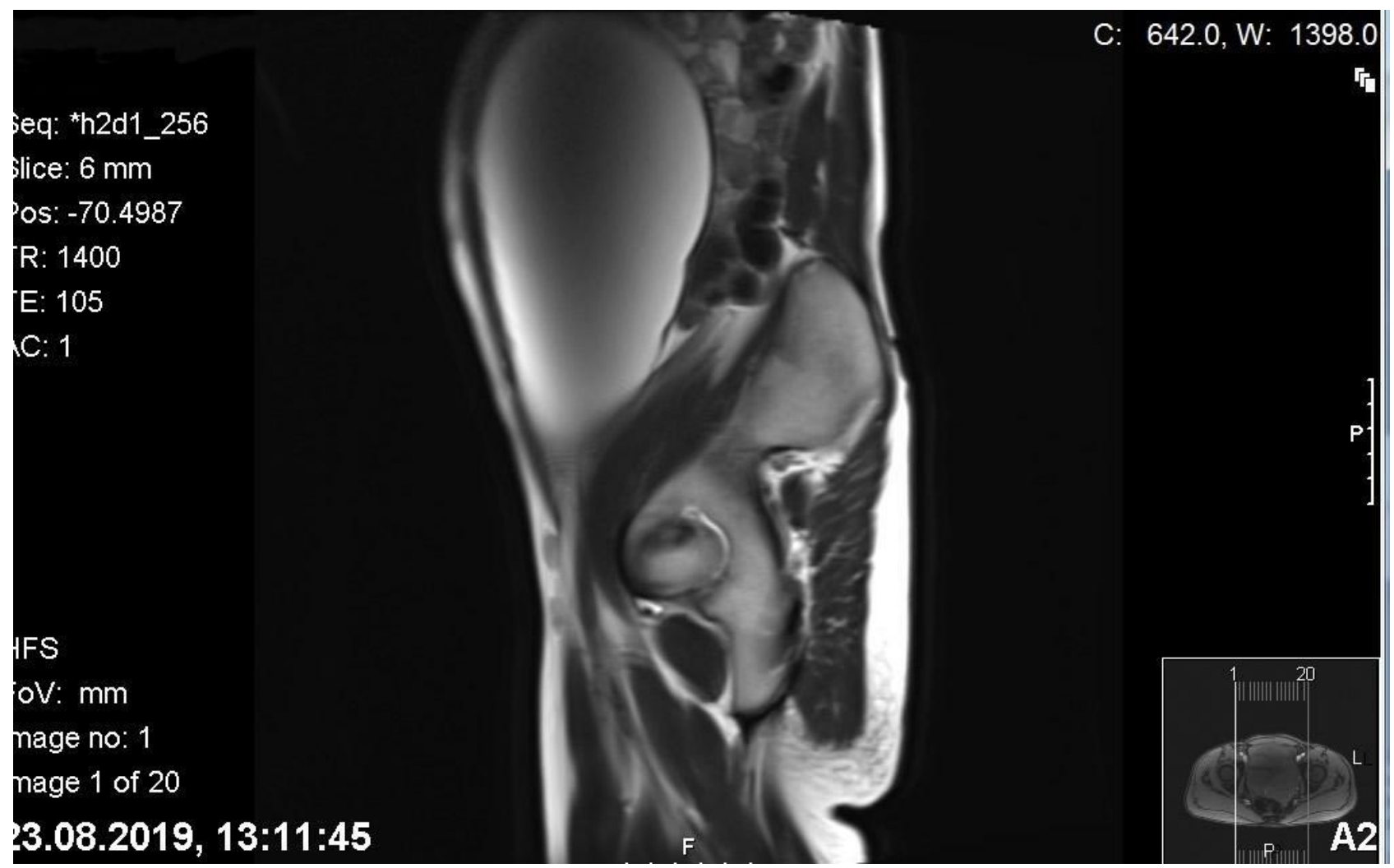

Şekil 2. Pelvik kistik kitlenin MRI görüntüsü. Kist pelvisten başlayıp diyafram altına kadar uzanmaktadır.

\section{Tartışma}

Kistik pelvik kitleler farklı organlardan köken alabilse de genellikle over kaynaklıdır.4 Seröz kistadenom ise tüm benign over tümörlerinin yaklaşık 20'ini oluştururlar. \%20-50 oranında bilateral görülen bu tümörlerin çapları nadiren 20 cm'nin üzerine çıkar. Benzer şekilde adneksiyal kitlelerin yaklaşık \%10'unu oluşturan5 paratubal kistlerde çok nadiren büyük boyutlara ulaşabilir.2 Broad ligament içine doğru büyüyen paratubal kistlerin genellikle over neoplazmları ile ayırıcı tanısı her zaman mümkün olmamaktadır. Bizim vakamızda da tüm batını dolduran kistik kitle boyutları dışında benign karakterli olsa da ovaryan lezyonlardan tam ayrımı yapilamadi. Orta hat insizyonu ile yapilan laparatomide tüm batını dolduran broad lig içinden kaynaklanan diğer pelvik organlarla ilişkisi olmayan kitle eksize edildi. Kitlenin patolojisi seröz kistadenom olarak değerlendirildi.

Büyük boyutlara ulaşmış pelvik kitleler farklı semptomlarla karşımıza çıkabilirler. Torsiyon, kist rüptürü ve hemorajiye neden olarak akut batına neden olsalar da en sik semptom müphem pelvik ağrıdır. Dört ay öncesine kadar şikâyeti olmayan vakamız da karında büyüme ve pelvik ağrı şikayeti ile hastanemize başvurdu.

Paratubal kistler için tedavi seçenekleri hastanın yaşı, fertilite arzusu ve lezyonun neoplastik durumuna göre değişir. Ultrasonografik incelemede basit görünümlü $10 \mathrm{~cm}$ 'den küçük lezyonlarda cerrahi tedavi gerekmezken daha büyük veya komplike kistlerde cerrahi tedavi düşünülmelidir. Cerrahide kistik kitlenin özeliğine göre endoskopik cerrahi düşünülebilir. Fakat büyük boyutlara sahip kistlerde kist rüptürü ve olası bir malignitenin iatrojenik yayılımı nedeniyle laparatomi doğru tedavi seçenek olabilir. Bizde bu vakada orta hat insizyonla laparatomi yaptık. Yine hasta 17 yaşında ve fertilite arzusu olduğu için sadece kist eksizyonu uyguladık. Frozen inceleme sonucu benign raporlanması üzerine cerrahiye son verdik.

Sonuç olarak ultrasonografide basit görünümlü pelvik kistlerde kist boyutu çok 
büyük olsa da ayırıcı tanıda paratubal kistler de düşünülmelidir. Tedavide hastanın yaşına, fertilite arzusuna ve neoplazmin maignite durumuna göre karar verilmelidir.

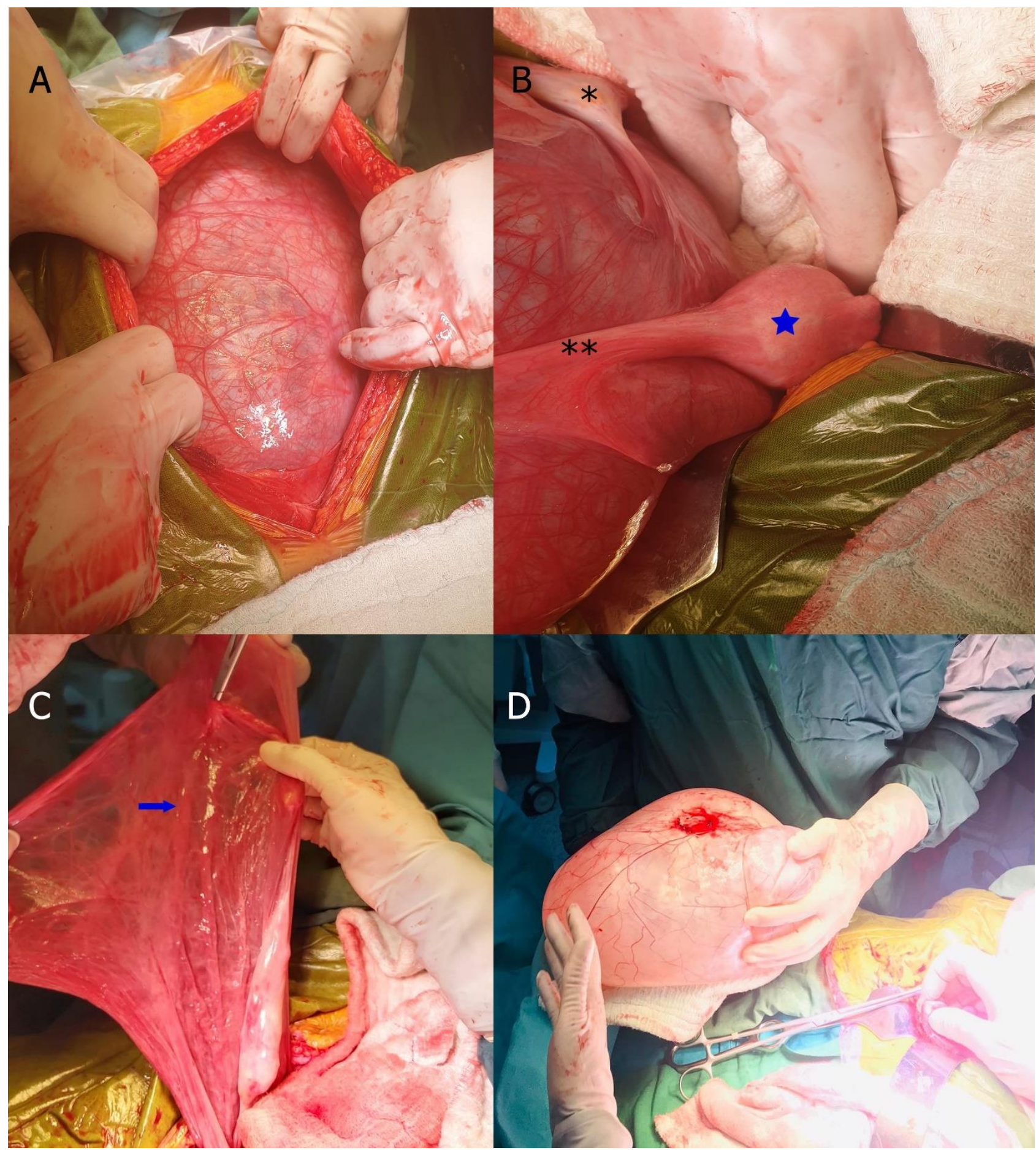

Sekil 3. Pelvik kitlenin ameliyat sırasındaki görüntüleri. A: batına ilk girişte lezyonun görünümü, B: kistik kitlenin tuba ${ }^{* *}$ ), over $\left({ }^{*}\right)$ ve uterus (mavi yıldız) ile komşuluğu, C: kist eksizyonundan sonra tuba uterinanın (mavi ok) seyri, D: çıkan kistik kitlenin görünümü.

\section{Araştırmanın Etik Boyutu}

Helsinki deklarasyonuna uyularak bu olgu sunumu için hastanın/vasinin yazılı onamı alınd1.

\section{Bilgilendirilmiş Onam}

$\mathrm{Bu}$ olgu sunumu için hastanın/vasinin yazılı onamı alınd1.

\section{Yazar Katkıları}

MB: Çalışmanın planlanması, verilerin elde edilmesi, makalenin yazılması, şekillerin oluşturulması, kontrol ve cerrahi işlem, NK: 
verilerin elde edilmesi, makalenin yazılması ve cerrahi işlem

\section{Teşekkürler}

Yok

\section{Çıkar Çatışması Beyanı}

Yazarların herhangi bir çıkara dayalı ilişkisi yoktur.

\section{Araştırma Desteği}

Yok

\section{Beyanlar}

$\mathrm{Bu}$ çalışma, 02-04 Mart 2020 tarihinde “15. Uludağ Jinekoloji ve Obstetrik Kış kongresinde (Bursa, Türkiye)" PS-16 numaralı poster olarak sunulmuştur.

\section{Hakem Değerlendirmesi}

Diş bağımsı.

\section{Kaynaklar}

1. Perlman S, Hertweck P, Fallat ME. Paratubal and tubal abnormalities. Semin Pediatr Surg. 2005;14:124-34.

2. Gölbaşı C, Taner CE, Ekin A, Hürcan E, Gümüş İ, Solakoğlu Kahraman D. Dev paratubal kisti olan bir genç kadın. Cukurova Med J 2016;41(3):573-576. Doi: 10.17826/cukmedj.237545.

3. Koc E, Turkyilmaz C, Atalay Y, Basaklar C, Bideci A. Neonatal ovarian cyst asociated with intestinal obstruction. Indian J Pediatr. 1997;64:555-7.

4. Kafadar S, Kafadar H. Karın Ağrısı Şikâyeti ile Gelen Ergen Kizlarda İmperfore Himene İkincil Hematokolpos. Adiyaman Üni. Sağlık Bilimleri Derg, 2017; 3(1):407-417.

5. Kiseli M, Caglar GS, Cengiz SD, Karadag D, Y1lmaz MB. Clinical diagnosis and complications of paratubal cysts: review of the literature and report of uncommon presentations. Arch Gynecol Obstet. 2012 Jun;285(6):1563-9. doi: 10.1007/s00404012-2304-8. 